\title{
The value of workforce data in shaping nursing workforce policy: A case study from North Carolina
}

\author{
Erin P. Fraher, PhD, MPP* \\ Department of Family Medicine, School of Medicine, University of North Carolina at Chapel Hill, Chapel Hill, NC
}

A R T I C L E I N F O

Article history:

Received 12 April 2016

Revised 4 October 2016

Accepted 18 October 2016

Available online November 1, 2016.

Keywords:

Nursing

Data

North Carolina

Workforce

Policy

\begin{abstract}
A B S T R A C T
Background: In 2015, the Institute of Medicine's Committee for Assessing Progress on Implementing the Future of Nursing recommendations noted that little progress has been made in building the data infrastructure needed to support nursing workforce policy.

Purpose: This article outlines a case study from North Carolina to demonstrate the value of collecting, analyzing, and disseminating state-level workforce data.

Methods: Data were derived from licensure renewal information gathered by the North Carolina Board of Nursing and housed at the North Carolina Health Professions Data System at the University of North Carolina at Chapel Hill.

Discussion: State-level licensure data can be used to inform discussions about access to care, evaluate progress on increasing the number of baccalaureate nurses, monitor how well the ethnic and racial diversity in the nursing workforce match the population, and investigate the educational and career trajectories of licensed practical nurses and registered nurses.

Conclusion: At the core of the IOM's recommendations is an assumption that we will be able to measure progress toward a "Future of Nursing" in which $80 \%$ of the nursing workforce has a BSN or higher, the racial and ethnic diversity of the workforce matches that of the population, and nurses currently employed in the workforce are increasing their education levels through lifelong learning. Without data, we will not know how fast we are reaching these goals or even when we have attained them. This article provides concrete examples of how a state can use licensure data to inform nursing workforce policy.

Cite this article: Fraher, E. P. (2017, APRIL). The value of workforce data in shaping nursing workforce policy: A case study from North Carolina. Nursing Outlook, 65(2), 154-161. http://dx.doi.org/10.1016/ j.outlook.2016.10.003.
\end{abstract}

\section{Introduction}

In 2011, the National Institute of Medicine's (IOM) Future of Nursing report highlighted the need to develop better nursing data systems to support workforce planning and policy as one of four national priorities (IOM 2011). In 2015, the IOM's Committee for
Assessing Progress on Implementing the Future of Nursing recommendations found that "little progress has been made on building a national infrastructure that could integrate the diverse sources of health workforce data; identify gaps; and improve and expand usable data not just on the nursing workforce but also on the entire health care workforce." (IOM, 2015) As the Committee noted, the lack of adequate workforce data

\footnotetext{
* Corresponding author: Erin P. Fraher, Department of Family Medicine, School of Medicine, University of North Carolina at Chapel Hill, Chapel Hill, NC 27599.

E-mail address: erin_fraher@unc.edu (E.P. Fraher).
} 
is not limited to nursing. One of the enduring themes of workforce reports published by the IOM is the absence of workforce data needed to support evidence-based policy. For example, in a 2014 report on "Graduate Medical Education that Meets the Nation's Health Needs," the IOM noted that the "United States has never established a data infrastructure to support an assessment of the health care workforce or the education system that produces it" (Institute of Medicine, 2014, p. 44).

Gaps in health workforce data at the state and national level are problematic in the context of rapid health system change as educators, employers, legislators, and funders struggle to evaluate the effect that new care delivery and payment models will have on the workforce. While some progress has been made in collecting national nursing data, more leadership, resources, and collaboration are needed to develop the robust, state-level data systems called for in the 2011 IOM report (Spetz, Cimiotti, \& Brunell, 2016). Numerous stakeholders have called for state licensure boards to collect, at the time of initial licensure and renewal, a common set of data elements on the demographic, practice, and geographic characteristics of the nursing workforce (IOM, 2015; Nooney et al., 2010; Nooney, 2013). Such an approach would enable statelevel data to be aggregated to the national level to create a much needed federal census of the nursing workforce.

A recent study by the Health Workforce Technical Assistance Center (HWTAC) found that health workforce data are collected in more than half of states (Armstrong, Forte, \& Moore, 2015), but the high fixed costs of establishing a system may prevent some states from collecting data through the licensure renewal process (IOM, 2015; Spetz, Cimiotti, Brunell, 2016). Another HWTAC study noted that licensure boards may also have concerns about data ownership and confidentiality as well as questions about whether workforce data collection is part of their mandate to protect the public (Gaul, Moore, \& Fraher, 2016). To address these challenges, nursing workforce stakeholders will need to demonstrate to licensure boards and policy makers how nursing data can be used to develop workforce policy that benefits patients and the health care system. The purpose of this article was to illustrate how nursing data have been used in North Carolina (NC) to inform discussions about access to care, evaluate progress on increasing the number of baccalaureate nurses, monitor how well the ethnic and racial diversity in the nursing workforce match the population, and investigate the educational and career trajectories of licensed practical nurses (LPNs) and registered nurses (RNs). The goal of this case study was to demonstrate the value of collecting, analyzing, and disseminating data that can be used to inform state nursing workforce policy discussions.

\section{Methods}

Data from this case study were drawn from the NC Health Professions Data System (HPDS), maintained by the Cecil G. Sheps Center for Health Services Research at the University of North Carolina at Chapel Hill. The HPDS is a long-standing and well-respected source of workforce data (Gresenz, Auerbach, \& Duarte, 2013). Data are collected annually from initial licensure and renewal forms for 19 licensed health professions in NC, including nurses. The data include information about the demographic, education, practice, and geographic characteristics of RNs, LPNs, and nurse practitioners (NPs) licensed to practice in the state since 1979. Data on certified nurse midwives (CNMs) are available back to 1985. Every year, the HPDS publishes a Data Book detailing the number of LPNs, RNs, CNMs, NPs, physician assistants, physicians, dentists, pharmacists, chiropractors, occupational therapists, occupational therapy assistants, physical therapists, physical therapist assistants, dental hygienists, optometrists, podiatrists, psychologists, psychological associates, and respiratory therapists in active practice by county and statewide. A common set of data elements is collected across the health professions, and a full list of variables contained in the data system can be found in the appendices of the Data Book (Spero et al., 2014). Because licensure is required to practice in the state, the data provide a complete census of the workforce in NC as of October 31 of each year. The longitudinal nature of the files also allows researchers to concatenate records over time to analyze individual-level education trajectories, career patterns, and geographic moves.

\section{Findings/Discussion}

The primary focus of the HPDS is to monitor trends in the supply and distribution of health professionals in the state. However, special reports are often undertaken at the behest of key stakeholders including the legislature, the NC Area Health Education Centers program, educational programs, and health systems. This next section outlines how HPDS data have been used to "tell stories" that have informed nursing workforce policy in the state. The goal of these analyses has been to translate nursing workforce data into powerful visualizations-tables, charts, and maps-that provide an objective, evidence-based source of information that can be used by nursing stakeholders in policy discussions.

\section{Educating Legislators}

Requests to open new nursing programs, change scopes of practice, or allocate funds to new nursing 
initiatives are debated in state legislatures across the country every year. To evaluate these requests, legislators want to know the "state of the state" of the nursing workforce. Having longitudinal data allows legislators to assess whether supply has kept pace with the state's population growth over time, and comparisons to U.S. data provide a picture of how the state's workforce compares to the national average. As Figure 1 shows, NC's per capita supply of nurses has outpaced the national average since 1990. More granular analyses of county-level data reveal that this growth has not been uniform across the state. For example, in NC, the gap in the supply of nurses between rural and urban has been widening over time. By 2014, urban areas of the state had 32 more RNs per 10,000 persons than rural areas (Fraher, 2016).

Objective workforce data play a critical role in contentious scope of practice discussions to balance anecdotal information provided by professional organizations that have a stake in the outcome of the debate. In early 2014, the NC General Assembly's Joint Legislative Committee on Health and Human Services appointed a subcommittee to determine whether CNMs should be allowed to practice midwifery in collaboration with, rather than under the supervision of, a physician. Having licensure data on both physicians and CNMs allowed analysts to capture information on the practice location and specialty of all practitioners providing obstetric care in the state. To determine if there might be problems with access to care for pregnant women in the state, licensure data were combined with information on the number of births by county. These analyses revealed that 25 counties did not have an obstetrical care providereither a CNM or a physician providing obstetric delivery services-and another 25 counties had more than 150 births per provider in 2014 compared with the state average of 103 births per provider (Figure 2). After reviewing the data, committee members proposed new legislative language permitting CNMs to practice independently following the completion of an initial period of collaboration with a physician or independently licensed CNM. That legislation did not pass in the 2013-2014 session but is still under review as part of Advance Practice Registered Nurse scope of practice reform in the state.

\section{Monitoring Progress Toward an $80 \%$ Baccalaureate-Prepared Workforce}

The 2010 IOM Future of Nursing report recommended that $80 \%$ of nurses hold a baccalaureate degree or higher in nursing by 2020. The Campaign for Action has produced a dashboard that tracks, among other outcomes, the country's progress toward the $80 / 20$ goal. The dashboard draws on survey data from the American Community Survey (ACS). The ACS is a nationwide survey conducted by the Census to gather reliable and timely demographic, social, economic, and housing data at the federal and state level. Because the ACS is a sample survey, estimates on nurses' educational achievement derived from the data include a sampling error. The sampling error is a statistical estimate of the difference between the level of educational attainment derived from the sample and the true level of education in the population-it is analogous to the "plus or minus" estimates given when pollsters report a candidate's lead in the polls. Because the ACS draws on a smaller sample of nurses in states with smaller nursing workforces, estimates of educational attainment in these states have wide sampling errors. This makes it difficult to estimate and track the percent of the workforce that has a baccalaureate degree.

State licensure data provide a much more precise estimate of progress toward the $80 / 20$ goal. Table 1 shows that between 2007 and 2013, the number of

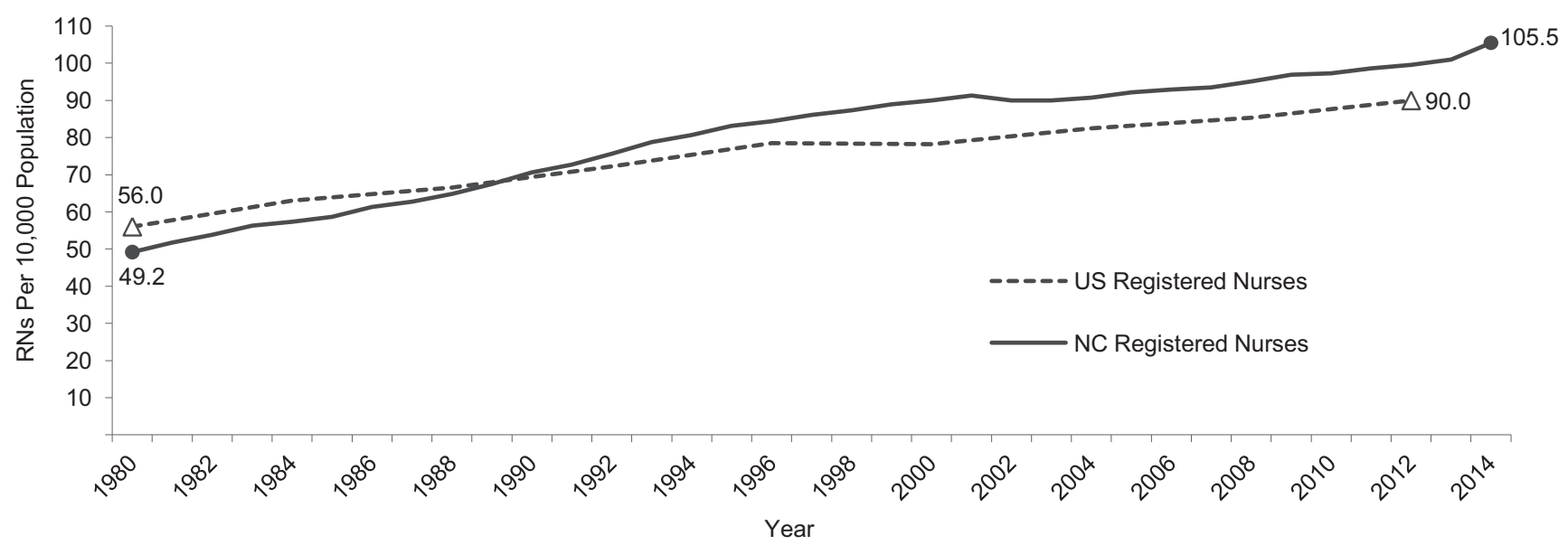

Figure 1 - Registered nurses (RNs) per 10,000 persons, United States (US) and North Carolina (NC), 1979 to 2014. Notes: Figure includes all licensed, active, in-state registered nurses as of October 31 of the respective year. Sources: North Carolina Health Professions Data System, with data from the North Carolina Board of Nursing, North Carolina Office of State Planning and National Sample Survey of Registered Nurses. 


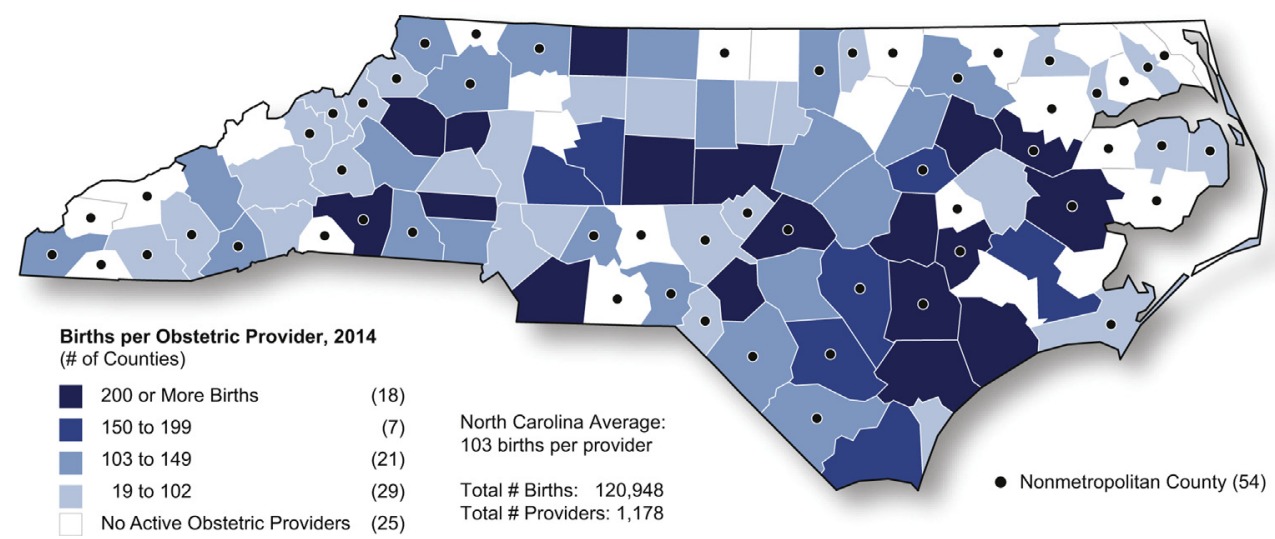

Figure 2 - Resident births per obstetric care provider, North Carolina, 2014. Note: Data include active, in-state certified nurse midwives (CNMs) who were licensed in North Carolina as of October 31, 2014, and active, instate, nonfederal, non-resident-in-training physicians who were licensed in North Carolina as of October 31, 2014, and reported that they provide obstetric deliveries. Providers are assigned to counties based on selfreported primary practice location. Sources: Providers: North Carolina Health Professions Data System, with data derived from the North Carolina Board of Nursing and North Carolina Medical Board, 2014. Resident Live Births: Department of Health and Human Services, Vital Statistics, linc.state.nc.us, accessed 9/27/2016. Nonmetropolitan counties: "core based statistical area" (CBSA) is the U.S. Census Bureau and Office of Management and Budget collective term for metropolitan and micropolitan statistical areas. Here, nonmetropolitan counties include micropolitan and counties outside of CBSAs, effective July 2015. Produced by: Program on Health Workforce Research and Policy, Cecil G. Sheps Center for Health Services Research, University of North Carolina at Chapel Hill.

nurses in NC with a BSN or higher increased more than the number with an ADN (10,747 vs. 4,308). However, the overall percentage of the workforce with a BSN or higher increased by just 5.5 points to $44.9 \%$ of the total workforce. These data highlight that significant progress toward reaching the $80 / 20$ goal will only happen if policy makers target both nurses in the pipeline and those already in practice. Regarding the pipeline, policy makers can increase the output of BSNs relative to ADNs and develop innovative programs that allow dual enrollment so that ADN nurses already in the pipeline can seamlessly enter a BSN program. Figure 3 shows that an increasing number of $\mathrm{ADN}$ nurses already in practice in NC are pursuing additional education, but efforts to make baccalaureate education affordable, convenient, and attractive need to be sustained to encourage currently practicing nurses to pursue the BSN.

State-level data are also important for tracking differences in practice patterns between ADN and BSN nurses. Such analyses are critical to understanding how the geographic and practice characteristics of the workforce may change as the country transitions from a predominantly ADN to BSN workforce. Analyses of NC data have shown that ADN nurses are twice as likely to practice in the state's rural and most economically distressed counties compared with nurses with a BSN or

\section{Table 1 - Active RNs by Highest Degree, North Carolina, 2007 to 2013}

\begin{tabular}{|c|c|c|c|c|c|c|c|c|c|c|}
\hline \multirow[t]{2}{*}{ Highest Degree } & \multicolumn{2}{|c|}{2007} & \multicolumn{2}{|c|}{2009} & \multicolumn{2}{|c|}{2011} & \multicolumn{2}{|c|}{2013} & \multirow{2}{*}{$\begin{array}{l}\text { No. Change } \\
2007-2013\end{array}$} & \multirow{2}{*}{$\begin{array}{l}\text { \% Point Change } \\
\text { 2007-2013 }\end{array}$} \\
\hline & No. & $\%$ & No. & $\%$ & No. & $\%$ & No. & $\%$ & & \\
\hline Diploma & 8,682 & 11.5 & 8,136 & 10.0 & 7,298 & 8.4 & 6,213 & 6.9 & $-2,469$ & -4.6 \\
\hline Associate & 31,013 & 41.0 & 33,320 & 40.8 & 34,622 & 40.0 & 35,321 & 39.1 & 4,308 & -1.8 \\
\hline $\begin{array}{l}\text { Baccalaureate or } \\
\text { higher in nursing }\end{array}$ & 29,784 & 39.3 & 33,250 & 40.7 & 36,939 & 42.7 & 40,531 & 44.9 & 10,747 & 5.5 \\
\hline $\begin{array}{l}\text { Baccalaureate or } \\
\text { higher outside } \\
\text { nursing }\end{array}$ & 6,240 & 8.2 & 7,014 & 8.6 & 7,662 & 8.9 & 8,238 & 9.1 & 1,998 & 0.9 \\
\hline Total & 75,719 & 100.0 & 81,720 & 100.0 & 86,521 & 100.0 & 90,303 & 100.0 & 14,584 & \\
\hline
\end{tabular}

Sources: North Carolina Health Professions Data System, 2007 to 2013 with data from the North Carolina Board of Nursing. Note. RNs, registered nurses.

Data include all licensed, active, in-state registered nurses as of October 31 of the respective year. Data on the highest degree was missing for about $10 \%$ of the workforce in each year. These nurses are excluded from the totals. 


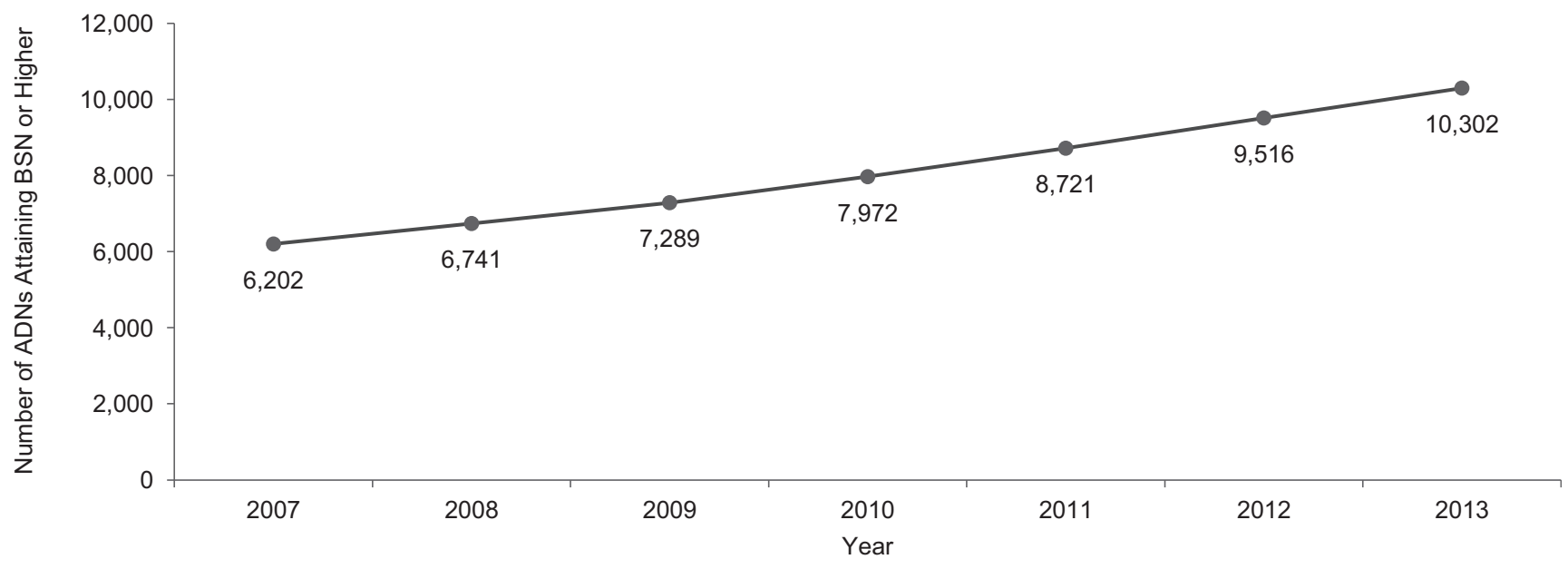

Figure 3 - Number of ADN nurses in the workforce who have gone onto a BSN or higher degree in nursing, North Carolina, 2007 to 2013. Notes: Figure includes licensed, active, in-state registered nurses as of October 31 of the respective year. Sources: North Carolina Health Professions Data System, 2007 to 2013 with data from the North Carolina Board of Nursing.

higher, as well as more likely to practice in needed specialties such as long-term care, geriatrics, home health, and mental health (Fraher, Spero, Gaul \& Minnotte, 2014; Fraher, Belsky, Gaul, \& Carpenter, 2010). A study by Kovner, Corcoran and Brewer (2011) that investigated the practice patterns of newly licensed nurses in 15 states found that approximately two-thirds of nurses work within 100 miles of where they grew up and 35.1\% practice within 15 miles of where they attended high school. These studies suggest that nurses are a relatively immobile group, and to ensure that underserved communities have an adequate workforce, policy makers need to develop BSN educational programs and clinical placements in rural communities; create online and satellite programs to deliver BSN education in rural areas; support ADN nurses currently in practice to go on to pursue the BSN; and encourage community college programs and university systems to develop articulation agreements that make it easier for nurses to seamlessly continue their education.

\section{Highlighting the Lack of Diversity in the Workforce}

The IOM's Committee for Assessing Progress on Implementing the Future of Nursing's recommendations highlighted the lack of diversity in the workforce and identified the need to "emphasize recruitment and retention of a diverse nursing workforce as a major priority for both the national Campaign and state Action Coalitions" (IOM, 2015). One key diversity measure is how well the racial and ethnic makeup of the workforce matches that of the population in a state. In North Carolina, only LPNs come close to matching the overall

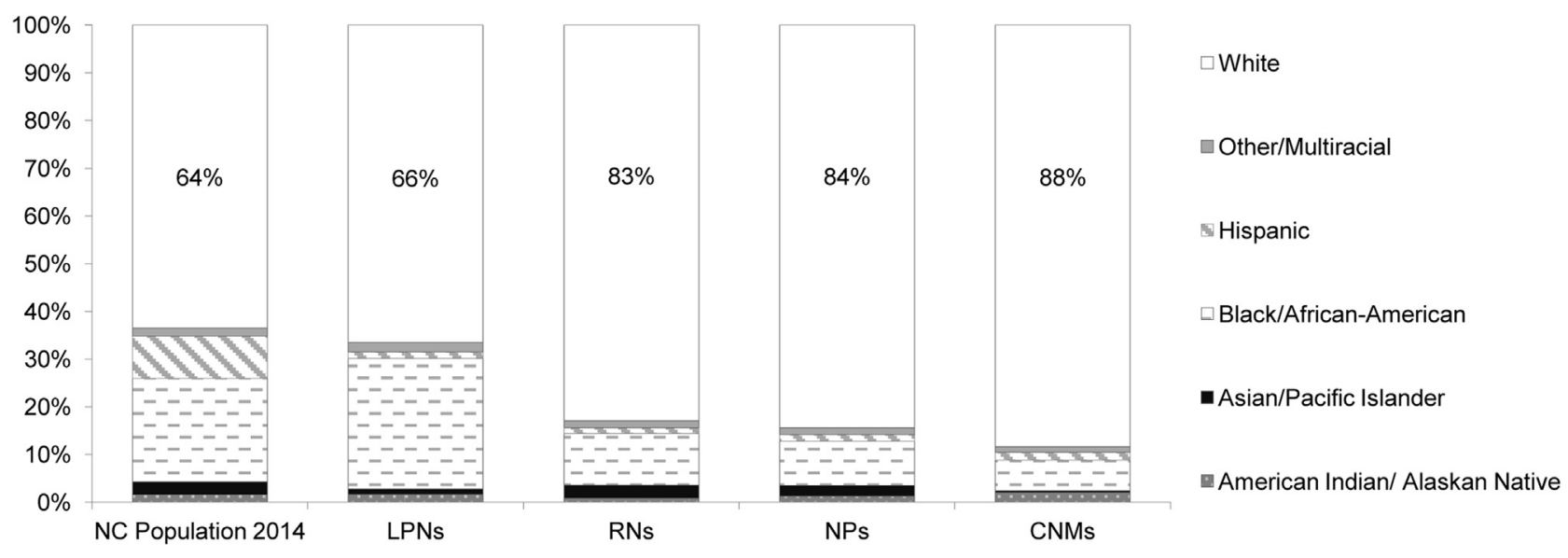

Figure 4 - Percent of nursing workforce and NC population by race/ethnicity, North Carolina, 2014. Notes: Figure includes all licensed, active, in-state nurses as of October 31, 2014. CNMs, certified nurse midwives; LPNs, licensed practical nurses; NPs, nurse practitioners; RNs, registered nurses. Sources: North Carolina Health Professions Data System, 2015, with data from the North Carolina Board of Nursing. 
$\square$ ADN $(n=34,975) \quad \square$ Baccalaureate or higher $(n=46,448)$

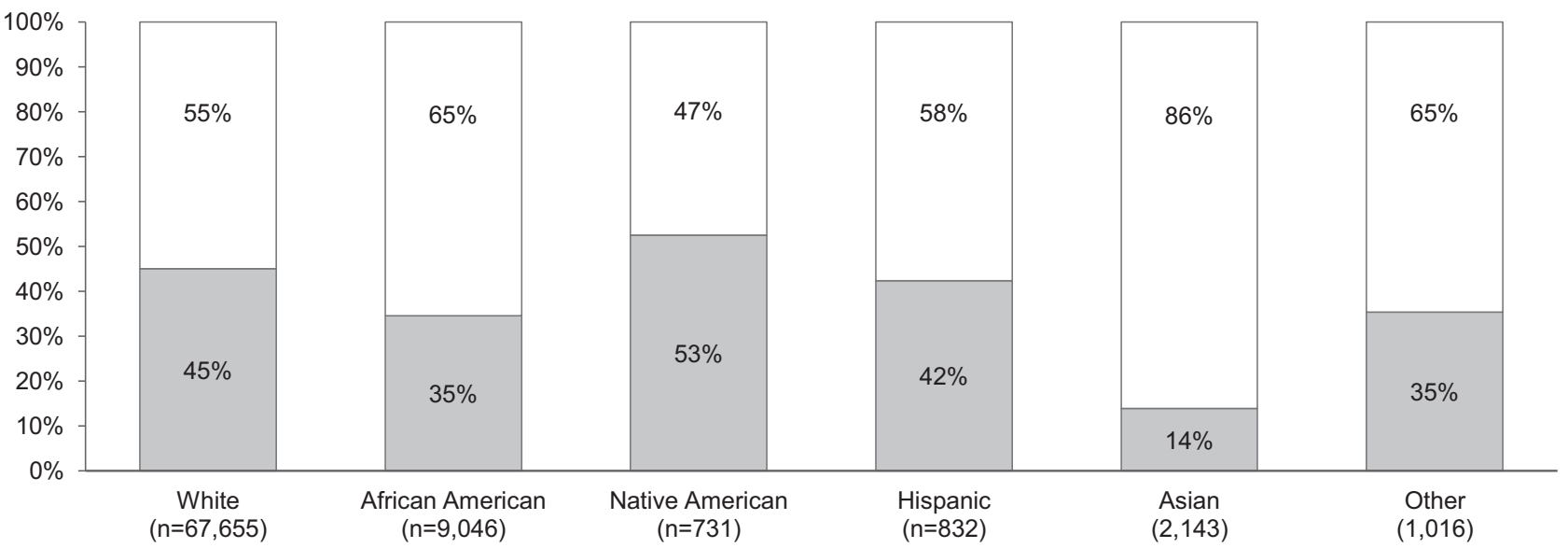

Figure 5 - North Carolina nursing workforce by race/ethnicity and highest degree, 2012. Notes: Figure includes all licensed, active, in-state nurses as of October 31, 2012. Race was missing for 150 registered nurses. Bacc, baccalaureate. Sources: North Carolina Health Professions Data System, 2015, with data from the North Carolina Board of Nursing.

diversity of the population. Figure 4 shows that $66 \%$ of the LPN workforce is white compared to $64 \%$ of the population, but even LPNs fall short in reaching parity with the Hispanic and Native American populations in the state. CNMs, RNs, and NPs are much less diverse than LPNs or the state's population.

One concern with increasing the entry-level credential of the workforce is the possibility that it could inhibit diversity unless resources are devoted to attracting and retaining African American, Native American, and Hispanic students. An analysis of the racial and ethnic diversity of the nursing workforce in North Carolina comparing those with an ADN vs. a baccalaureate or higher degree ${ }^{1}$ reveals a somewhat surprising finding. A greater percentage of African American nurses have a baccalaureate degree or higher in nursing compared with white nurses (65\% vs. $55 \%$ ) (Figure 5). This finding may be unique to North Carolina since $41 \%$ of African American nurses who hold a BSN attended one of the state's four nursing programs based in Historically Black Colleges and Universities. These data underscore the important role that educational programs play in increasing the diversity of the workforce and suggest the need for targeted efforts to ensure that any plans to expand nursing enrollment include resources targeted to recruiting and matriculating students from underrepresented minorities.

\section{Tracking Career and Educational Trajectories}

Monitoring annual trends using cross-sectional data is important to identify changes in the workforce that may signal emerging shortages in certain geographic

\footnotetext{
${ }^{1}$ Note: Nurses with a diploma are excluded from this analysis.
}

locations or specialties that could adversely affect patients' access to care. However, having individuallevel, panel data allows researchers to track nurses over time to investigate their educational and career trajectories. For example, multiple researchers have used North Carolina's data to investigate nurses' educational trajectories. In 2007, Bevill et al. examined two cohorts of nurses - one that graduated in 1984 and another that graduated in 1994-to investigate the factors associated with nurses continuing their education (Bevill et al., 2007). They found that younger age, male sex, and belonging to a racial or ethnic minority were associated with increased likelihood of pursing additional education. A more recent study by Jones et al. (2016) echoed the findings by Bevill et al; they found that LPNs were more likely to transition to being an RN if they were male; were Asian, American Indian, or from an other racial/ethnic background; worked in a hospital in-patient setting; and were from a rural area (Jones et al., 2016). These findings bode well for achieving two of the IOM's recommendationsincreasing the educational attainment and the diversity of the nursing workforce.

\section{Conclusions}

At the core of the IOM's recommendations is an assumption that we will be able to measure progress toward a "Future of Nursing" in which $80 \%$ of the nursing workforce has a BSN or higher, the racial and ethnic diversity of the workforce matches that of the population, and nurses currently employed in the workforce are increasing their education levels through lifelong learning. Without data, we will not know how fast we are reaching these goals or even 
when we have attained them. This article has outlined a case study of how nursing licensure data have been used in North Carolina to inform discussions about access to care, evaluate progress on increasing the number of baccalaureate nurses, monitor how well the ethnic and racial diversity in the nursing workforce match the population, and investigate the educational and career trajectories of LPNs and registered nurses. The goal of the article has been to show how nursing workforce data have been used to create powerful data "stories" that have been used to inform nursing workforce policy in the state.

The obstacles to creating a robust nursing workforce data system are numerous, but they are more likely to be overcome if nursing stakeholders can show the "return on investment" for funds spent on collecting and analyzing data. This return on investment will be measured in how much policy makers-legislators, educators, health systems, the nursing profession, and other health professions-begin to see how the shared benefits of having a statewide data system outweigh the costs of developing and maintaining one. Nursing workforce stakeholders will gain "a seat at the table" if they come armed with data that provide evidence to justify funding requests, influence nursing education program planning, inform regulatory debates, and identify shortage areas (Fraher et al., 2013c). To get there, state nursing stakeholders will need to engage licensing bodies in collecting health workforce data and be responsive to their concerns around data confidentiality and ownership, costs, and how workforce data collection relates to their regulatory mission. The Campaign for Action is encouraging states to work with licensure boards to develop minimum data sets and has produced a series of fact sheets to help guide these efforts (Fraher, Gaul, \& Spero, 2013a, 2013b, 2013c). Once the data collection system has been developed, partnering with a university or nursing workforce center is needed to provide analytic support, expertise in data visualizations, and geographic information systems.

\section{Acknowledgments}

The author would like to thank Erica Richman and Julie Spero for data collection and analysis, and Katie Gaul for mapping providers per births in the state. This work was funded by the Robert Wood Johnson Foundation, Future of Nursing: Campaign for Action Research Manager, Grant \# 72895.

\section{R E F E R E N C E S}

Armstrong, D. P., Forte, G. J., \& Moore, J. (2015). Inventory of State Health Workforce Data Collection. Rensselaer, NY: Health Workforce Technical Assistance Center, Center for Health
Workforce Studies, School of Public Health, SUNY Albany. Retrieved from http://www.healthworkforceta.org/wpcontent/uploads/2015/11/HWTAC_Data_Collection_ Inventory_Report_2015.pdf

Bevill, J. W., Jr., Cleary, B. L., Lacey, L. M., \& Nooney, J. G. (2007). Educational Mobility of RNs in North Carolina: Who Will Teach Tomorrow's Nurses. A Report on the First Study to Longitudinally Examine Educational Mobility Among Nurses. American Journal of Nursing, 107(5), 60-70.

Fraher, E. (2016). The Nursing Workforce: Trends and Challenges. A presentation to the North Carolina's Joint Legislative Workforce Development System Reform Oversight Committee. Retrieved from http://www.shepscenter.unc. edu/wp-content/uploads/2016/04/Fraher_NCGA_3_1_16_ FINAL.pdf

Fraher, E., Belsky, D. W., Gaul, K., \& Carpenter, J. (2010). Factors affecting attrition from associate degree programs in North Carolina. Cahiers de Sociologie et de Démographie Médicales, 50(2), 213-246.

Fraher, E., Gaul, K., \& Spero, J. (2013a). How States Can Develop Better Nursing Workforce Data Systems. Princeton, NJ: Robert Wood Johnson Foundation. Retrieved from http://www shepscenter.unc.edu/wp-content/uploads/2014/01/TWO-RWJ_ Organization_-September-2013-Final.pdf

Fraher, E., Gaul, K., \& Spero, J. (2013b). What Data States Can Collect to Build Better Nursing Workforce Data Systems. Princeton, NJ: Robert Wood Johnson Foundation. Retrieved from http:// www.shepscenter.unc.edu/wp-content/uploads/2014/01/ THREE-RWJ_DataCollection_September-2013-Final.pdf

Fraher, E., Gaul, K., \& Spero, J. (2013c). Why States Need to Build Better Nursing Workforce Data Systems. Princeton, NJ: Robert Wood Johnson Foundation. Retrieved from http://www shepscenter.unc.edu/wp-content/uploads/2014/01/ONE-RWI_ Motivation_September-2013-Final.pdf

Fraher, E., Spero, J., Gaul, K., \& Minnotte, M. (2014). Trends in the Supply and Distribution of Obstetric Care Providers in North Carolina. Retrieved from http://www.shepscenter.unc.edu/wp-content/ uploads/2016/04/Fraher_NCGA_CNMs_02_26_14_FINAL.pdf

Gaul, K., Moore, J., \& Fraher, E. (2016). Collaborating with Licensing Bodies in Support of Health Workforce Data Collection: Issues and Strategies. Albany, NY: Health Workforce Technical Assistance Center. Retrieved from http://www.healthworkforceta.org/ wp-content/uploads/2016/05/HWTAC_TA-to-States_Brief.pdf

Gresenz, C. R., Auerbach, D. I., \& Duarte, F. (2013) Opportunities and Challenges in Supply-Side Simulation: Physician-Based Models. Health Services Research, 48(2pt2), $696-712$.

Institute of Medicine Committee on the Future of Nursing (IOM). (2011). The Future of Nursing: Leading Change, Advancing Health. Washington, DC: National Academy of Sciences.

Institute of Medicine Committee for Assessing Progress on the Institute of Medicine Report the Future of Nursing. (2015). Washington, DC: National Academy of Sciences.

Institute of Medicine. (2014). Graduate Medical Education that Meets the Nation's Health Needs. Washington, DC: National Academies Press.

Jones, C. B., Toles, M., Knafl, G. J., \& Beeber, A. S. (2016). An Untapped Resource in the Nursing Workforce? Licensed Practical Nurses Who Transition to Become Registered Nurses. Chapel Hill, NC: Carolina Center for Health Workforce Research. (work in progress). Retrieved from http://www.shepscenter.unc.edu/ project/pathways-nursing-careers-transitions-role-practicenurse-registered-nurse-north-carolina/

Kovner, C. T., Corcoran, S. P., \& Brewer, C. S. (2011). The relative geographic immobility of new registered nurses calls for new strategies to augment that workforce. Health Affairs, 30(12), 2293-2300. 
Nooney, J. G., Cleary, B. L., Mouton, P., Wiebusch, P. L., Murray, J. L., Yore, M., \& Brunell, M. L. (2010). Toward standardization (part 1): Assessment of state and national nursing workforce data sources. Policy, Politics, \& Nursing Practice, 11(3), 173-183.

Nooney, J. G. (2013). NCHWA's Nursing Workforce Research and Activities. Washington DC: National Center for Health Workforce Analysis, HRSA, DHHS. Retrieved from http:// docplayer.net/12838193-Nchwa-s-nursing-workforceresearch-activities-and-findings.html
Spero, J., Terry, J., Lavoie, K., Gaul, K., Ricketts, T., Richman, E., \& Fraher, E. (2014). North Carolina Health Professions Data Book. Retrieved from http://www.shepscenter.unc.edu/ workforce_product/2014-north-carolina-healthprofessions-data-book/

Spetz, J., Cimiotti, J. P., \& Brunell, M. L. (2016). 2016 Improving Collection and Use of Inter-Professional Health Workforce Data: Progress and Peril. Nursing Outlook, 64(4), 377-384. 